\title{
PENGARUH MANUVER JARINGAN DISTRIBUSI 20 KV TERHADAP INDEKS KEANDALAN PENYULANG BT07 BATULICIN
}

\author{
Alif Karnandi Ode ${ }^{1}$, Moethia Faridha ${ }^{2}$ \\ Prodi Teknik elektro, Fakultas Teknik, Universitas Islam Kalimantan ${ }^{1,2}$ \\ $\underline{\text { Alifkarnandi8@gmail.com }}$, $\underline{\text { bariethia@gmail.com }}{ }^{2}$
}

\begin{abstract}
Abstrak - Keandalan suatu sistem tenaga listrik berkaitan dengan kualitas, kontinuitas penyaluran dayanya. Penyaluran daya listrik ditandai dengan pasokan daya yang terus menerus atau meminimalisir pemadaman. Salah satu yang berpengaruh di dalam kontinyuitas penyaluran daya listrik adalah pemilihan jenis konfigurasi jaringan. Konfigurasi Radial yang sederhana diangap tidak dapat memenuhi keandalan suatu sistem distribusi oleh karena itu dibuat bentuk variasinya berupa Konfigurasi Loop (SPLN No.59 Tahun 1985). Konfigurasi Loop merupakan gabungan dari dua buah struktur jaringan radial, dimana pada ujung dari dua buah jaringan di pasang sebuah saklar (switch) berupa Motorized atau LBS.
\end{abstract}

Manuver jaringan kegiatan rekayasa jaringan terhadap operasi normal dari akibat gangguan/pekerjaan jaringan sehingga tercapainya kondisi penyaluran tenaga listrik yang maksimal. Di dalam melakukan manuver jaringan perlu diperhatikan kapasitas peralatan jaringan berkaitan dengan beban maksimal yang dapat dipikul, seperti PMT dan Recloser. Untuk melakukan manuver direkomendasikan memilih penyulang dengan rugi saluran paling kecil sehingga daerah padam dapat diminimalisir namun kualitas listrik tetap dapat dipertahankan. Bagi penyulang BTL07 terdapat alternatif berbeda untuk setiap kondisi section yang padam. Jika section yang berada pada zona 1 atau daerah sepanjang PMT hingga
Recloser pertama padam, urutan altenatif manuvernya melalui penyulang BTL01 dan BTL05. Sedangkan jika zona 2 padam, urutan altenatif manuvernya melalui penyulang PLJ01 dan PLJ02. Sehingga diperlukan proses backup penyulang BTL07 terhadap penyulang lain dan pengaruh manuver penyulang BTL07 pada perkembangan jaringan distribusi $20 \mathrm{kV}$ dan keandalan jaringan distribusi terhadap gangguan yang dihitung dari Indeks saidi saifi, losses maupun ENS (Energy Not Served).

Sistem loop sebagai uji coba yang mempertemukan beberapa penyulang melalui titik key point Motorized maupun Recloser dengan penyulang BTL07 saat dilakukan simulasi dapat menanggung pelimpahan beban yang diberikan oleh penyulang BTL07 yang mencapai hingga 8.6 MW meyebabkan kenaikan jarak penyuplaian dari $41.6 \mathrm{kms}$ menjadi 66.7 $\mathrm{Kms}$ dengan drop tegangan yang terjadi maksimal penurunan $1 \mathrm{KV}$ dengan tegangan supplai dari GI Batulicin telah dinaikan menjadi $21 \mathrm{KV}$, hal ini dilakukan untuk menjaga standar kestabilan tegangan ujung.

Kata Kunci: Konfiurasi Jaringan, Indeks Keandalan

\section{PENDAHULUAN}

Perkembangan perekonomian yang semakin maju menyebabkan meningkatnya kebutuhan pasokan tenaga listrik yang mencukupi bagi seluruh konsumen 
masyarakat baik umum, industri, pemerintahan maupun gedung-gedung perkantoran. Khususnya di daerah provinsi Kalimantan selatan, dimana hasil alam yang terkandung di Kalimantan selatan melimpah, mulai dari sektor perkebunan dan pertambangan.

Menurut data UP2D Kalselteng dari 16 Gardu Induk yang melayani kelistrikan Provinsi Kalimantan selatan tahun 2019, pemakaian energi listrik mengalami peningkatan dengan total beban yang telah disalurkan dari Gardu Induk ke pelanggan sebesar 4.351,29 GWh sepanjang tahun 2019, data ini mengalami peningkatan dari tahun-tahun sebelumnya sebesar $41 \%$, dimana tahun 2018 sebelumnya sebesar 2174,04 GWh dan tahun 2017 sebesar 1272,61 GWh. Salah satunya didaerah Batulicin, jumlah pelanggan telah mencapai 83.426 pelanggan dan panjang jaringan distribusi $20 \mathrm{kV}$ sepanjang 1.005 $\mathrm{Kms}$ dengan total energi listrik yang terus berkembang dari tahun sebelumnya 77 GWh tahun 2017, 126 GWh tahun 2018 dan 299 GWh tahun 2019 telah disalurkan oleh Gardu Induk Batulicin.

Dari data terakhir bulan maret 2020, energi listrik yang telah disalurkan sebanyak 91 GWh, maka permintaan beban dan pasokan daya listrik semakin meningkat sehingga dibutuhkan sistem tenaga listrik yang handal, saat ini total beban puncak Batulicin sebesar 29,6 MW.

Untuk mengatasi Persebaran pelanggan yang meluas, maka jaringan distribusi dipecah menjadi beberapa jurusan sebelum keluar dari gardu induk menuju gardu penghubung dan gardu distribusi, yang biasa disebut dengan feeder atau penyulang. Masing-masing mempunyai besar beban dan jumlah pelanggan yang bervariasi, seiring dengan perkembangan pelanggan dan kerapatan beban pada penyulang maka keandalan jaringan perlu diperhatikan, salah satunya adalah penyulang BTL07 dengan jumlah pelanggan sebanyak 13.478 pelanggan, beban puncak rata-rata $6 \mathrm{MW}$ sampai 8 MW dan panjang penyulang 41,6 Kms yang merupakan penyulang kota di Batulicin dari 7 Penyulang yang ada di Gardu Induk Batulicin.

Apabila terjadi gangguan, kerugian disisi penyedia listrik dalam hal ini PT PLN Unit Layanan Pelanggan Batulicin tak dapat dihindari, maka akan berakibat pada indeks keandalan saidi dan saifi maupun ENS (Energy Not Served). Ditahun 2019 telah terjadi gangguan jaringan $20 \mathrm{kV}$ secara komulatif sebanyak 190 kali dengan durasi padam selama 1.728,79 menit di Batulicin. Untuk penyulang BTL07 telah terjadi gangguan sebanyak 17 kali dengan durasi padam selama 7 jam 43 menit (463 menit) dengan total beban terakhir sebesar $43,4 \mathrm{~mW}$ jika akumulasikan maka ENS dari padamnya penyulang ini adalah 20.094,2 $\mathrm{mW}$ dalam nilai uang sebesar Rp 491.396.963, -. Gangguan yang terjadi dipenyulang tersebut dapat disebabkan dari faktor internal dan eksternal, salah satunya yang mendominasi adalah faktor eksternal yaitu alam/petir. Gangguan ini tidak dapat diprediksi lokasi terjadinya, namun akibat terparah dari gangguan ini adalah putusnya jaringan distribusi $20 \mathrm{kV}$ ke gardu-gardu distribusi mengakibatkan padam pada pelanggan serta saat gangguan ini terjadi, perbaikan harus segera dilakukan secepatnya oleh petugas karena tidak adanya backup tegangan yang dapat mensupply.

Dengan konfigurasi jaringan distribusi penyulang BTL07 tanpa backup 
jaringan, maka saat terjadi gangguan dilokasi tertentu daerah lain yang disupply oleh penyulang BTL07 akan ikut padam yang akan berpengaruh pada keandalan jaringan distribusi penyulang BTL07. Salah satu cara untuk meningkatkan kontinuitas pasokan listrik adalah dengan mengoptimalkan kemampuan suatu penyulang dalam melakukan pelimpahan beban dijaringan, sehingga kondisi penyaluran tenaga listrik yang maksimal akan tetap tercapai dan mampu meminimalisir tingkat pemadaman. Kemampuan penyulang yang dimaksud ialah kemampuan sistem jaringan dalam mengatasi gangguan ataupun pemeliharaan, dengan cara menyediakan minimal dua penyulang yang siaga sehingga apabila sewaktu-waktu terjadi pemadaman pada salah satu penyulang, maka penyulang lainnya dapat menjadi backup dengan masih memperhatikan kualitas tegangan pelayanan sehingga tidak terjadi drop tegangan yang akan mengakibatkan kerusakan pada sisi peralatan pendistribusian dan juga peralatan pelanggan serta beban maksimal yang feeder pembantu dalam hal ini untuk kerja feeder BTL07 dalam mengatasi pembebanan yang semakin berkembang.

Adapun alasan penulis mengambil judul tersebut untuk memaksimalkan pemakaian beban pada pelanggan dan meningkatkan keandalan pada jaringan dsitribusi, serta supplai tenaga listrik cadangan yang dapat mensuplai tegangan tanpa adanya drop tegangan apabila terjadi gangguan pada penyulang dalam hal ini adalah penyulang BTL07 maka perlu dilakukan simulasi metode manuver jaringan distribusi $20 \mathrm{KV}$.

\section{METODE PENELITIAN}

\section{A. Jenis Penelitian}

Penelitian ini merupakan penelitian eksperimen pada sistem distribusi pada wilayah kerja PLN ULP Batulicin, tepatnya data primer dari pengukuran beban penyulang BTL07. Penelitian dilakukan dengan membandingkan losses dan drop tegangan terkecil menggunakan 4 (empat) data untuk menentukan titik perpotongan rekonfigurasi manuver jaringan. Data yang digunakan dalam analisa penelitian.

1. Single line diagram Penyulang BTL07

2. Data beban puncak penyulang

3. Data tiap titik beban

4. Data panjang penyulang

\section{B. Tahapan Penelitian}

1. Studi Literatur

Pengolahan data dengan membaca literatur-literatur dan mempelajari mengenai jaringan ditribusi $20 \mathrm{kV}$, struktur jaringan radial dan loop, analisis aliran daya, manuver jaringan distribusi.

2. Pengambilan Data

Pengumpulan data berupa parameter jaringan, single line diagram dan beban penyulang untuk data PSS Sincal untuk simulasi jaringan.

\section{Analisa Data dan Hasil}

Mengolah data hasil dilapangan untuk data posisi manuver rekonfigurasi jaringan penyulang BTL07.

Hasil dari titik perpotongan opsi untuk rekonfigurasi manuver menentukan baik tidaknya BTL07 dalam melakukan konfigurasi jaringan terhadap penyulang lain, sehingga pada saat terjadi gangguan atau pemeliharaan proses manuver yang telah dibuat tidak menyebabkan mengalami drop tegang dan losses yang 
tinggi. Data gangguan penyulang 7 bulan sebelumnya juga ikut disinkronkan dengan proses manuver sehingga dapat nilai yang akan menjadi acuan kondisi yang seharusnya dilakukan manuver jaringan apabila terjadi gangguan sehingga Saidi, Saifi dan ENS (Energy Not Served) dapat diminimalkan.

\section{HASIL ANALISA}

\section{A. Simulasi Sebelum Manuver}

1. Simulasi BTL07 - MTRZ Big Coffie

Pada kondisi ini posisi tegangan Penyulang BTL07 sebelum melakukan manuver jaringan, tegangan ujung pada MTRZ Big Coffie dari kondisi normal 20 $\mathrm{KV}$ turun menjadi $17.6 \mathrm{KV}$ dikarenakan jarak pengiriman tegangan mencapai 21,3 $\mathrm{Kms}$, pengiriman tegangan yang menanggung beban sebesar $2.4 \mathrm{MW}$, berdampak pada Penyulang ini, dimana terjadi penurunan tegangan sebesar 2.4 KV. Sebelumnya posisi tegangan trafo gardu induk Batulicin belum mengalami kenaikan disebabkan kondisi normal pada outgoing trafo gardu induk Batulicin menuju penyulang.

2. Simulasi BTL07 - MTRZ 5 OKT

Pada kondisi ini posisi tegangan Penyulang BTL07 sebelum melakukan manuver jaringan, tegangan ujung pada MTRZ 5 OKT kondisi normal $20 \mathrm{KV}$ turun menjadi $17.7 \mathrm{KV}$ sebelumnya posisi tegangan trafo gardu induk Batulicin belum kenaikan, dengan jarak pengiriman tegangan sejauh $22 \mathrm{Kms}$ terjadi penurunan tegangan sebesar $2.3 \mathrm{KV}$.

3. Simulasi BTL07 - MTRZ Kompi 1 Pada kondisi ini posisi tegangan Penyulang BTL07 sebelum melakukan manuver jaringan, tegangan ujung pada MTRZ Kompi 1 dari kondisi normal 20 $\mathrm{KV}$ turun menjadi $18.7 \mathrm{KV}$ sebelumnya posisi tegangan trafo gardu induk Batulicin belum mengalami kenaikan, dengan jarak pengiriman tegangan sejauh $13.5 \mathrm{Kms}$. Penyulang ini terjadi penurunan tegangan sebesar 1,3 KV.

4. Simulasi BTL07 - MTRZ Polsek

Pada kondisi ini posisi tegangan Penyulang BTL07 sebelum melakukan manuver jaringan, tegangan ujung pada MTRZ Polsek dari kondisi normal $20 \mathrm{KV}$ turun menjadi $17,42 \mathrm{KV}$ sebelumnya posisi TAP Trafo GI Batulicin belum kenaikan, dengan jarak pengiriman tegangan sejauh 23.6 Kms. Penyulang ini terjadi penurunan tegangan sebesar 2,58 KV.

B. Simulasi Setelah Manuver

1. Simulasi BTL07 - MTRZ Big Coffie Manuver

Pada kondisi ini posisi tegangan Penyulang BTL07 telah melakukan manuver jaringan, tegangan ujung pada MTRZ Big Coffie dengan penyuplaian penyulang PLJ01 beban eksisting 0,5 MW dengan adanya penambahan beban dari sebagain penyulang BTL07. Dari kondisi normal $20 \mathrm{KV}$ turun menjadi $19.4 \mathrm{KV}$ sebelumnya posisi tegangan trafo gardu induk Batulicin belum mengalami kenaikan dengan jarak pengiriman tegangan sejauh $9.4 \mathrm{Kms}$

\section{Simulasi BTL07 - MTRZ 5 OKT} Manuver

Pada kondisi ini posisi tegangan Penyulang BTL07 telah melakukan manuver jaringan, tegangan ujung pada MTRZ 5 OKT dengan penyuplaian penyulang BTL01 beban eksisting 3 MW dengan jarak pengiriman tegangan sejauh $32 \mathrm{Kms}$ dan posisi tegangan trafo gardu induk Batulicin belum mengalami kenaikan. Kondisi 
normal $20 \mathrm{KV}$ mengalami penurunan sebesar 3.6 KV menjadi $16.4 \mathrm{KV}$.

\section{Simulasi BTL07 - MTRZ Kompi 1}

Pada kondisi posisi tegangan Penyulang BTL07 telah melakukan manuver jaringan, tegangan ujung pada MTRZ Kompi 1 dengan penyuplaian penyulang BTL05 beban eksisting 1 MW dengan jarak pengiriman tegangan sejauh $15,7 \mathrm{Kms}$ dengan tegangan kirim sampai ujung jaringan $18.4 \mathrm{KV}$.

\section{Simulasi BTL07 - MTRZ Polsek}

Pada kondisi ini posisi tegangan Penyulang BTL07 telah melakukan manuver jaringan, tegangan ujung pada MTRZ Polsek dengan penyuplaian penyulang PLJ02, PLJ02 tidak mempunyai beban eksisting dengan jarak pengiriman tegangan sejauh 9,6 Kms namun jika dicoba dengan kondisi tegangan normal 20 $\mathrm{KV}$ dengan mengambil beban manuver sebagian daerah maka terjadi penurunan tegangan menjadi $19 \mathrm{KV}$.

\section{Analisa Hasil Simulasi}

Hasil simulasi manuver penyulang BTL07, beban penyulang yang menerima pelimpahan beban dari penyulang BTL07 terjadi beberapa penurunan pada beberapa titik manuver. Sedangkan pada drop tegangan terendah sebesar $18.2 \mathrm{KV}$ pada ujung jaringan, penerunan ini tidak berlangsung lama karena hanya terjadi pada jam beban puncak 20.00 berpengaruh signifikan sehingga disisi gardu distribusi namun dapat disesuaikan posisi tap trafo, pada tap trafo 6 untuk menerima tegangan $400 \mathrm{~V}$ pada jaringan JTR 3 phase sedangkan untuk tegangan $20 \mathrm{KV}$ dan 20.5 $\mathrm{KV}$ pada tap 3 atau 2 untuk penyesuain tegangan $400 \mathrm{~V}$ pada jaringan JTR 3 phase sesuai dengan spesifikasi trafo distribusi dilapangan. Losses pada jaringan SUTM juga mengalami peningkatan dari kondisi awal $267 \mathrm{kWh}$ sebelum manuver menjadi $341 \mathrm{kWh}$ dalam waktu berjalan, dari hasil simulasi ini apabila dilakukan manuver dalam waktu lama tidak akan memperburuk kondisi di jaringan. Manuver yang terjadi pada penyulang BTL07 dapat menyesuikan dengan trafo distribusi pelanggan untuk perkembangan beban kedepannya karena apabila terjadi gangguan, penyulang ini siap melakukan manuver pelimpahan beban ke penyulang lainnya.

Dalam operasi backup ini, peran LBS dan Motorized dapat dioptimalisasi dalam membentuk sistem loop pendukung penyulang BTL07. Apabila terjadi gangguan bersifat sementara maka jaringan akan kembali normal kembali. Tetapi apabila gangguan bersifat permanent maka recloser Sampurna akan Lock Out apabila gangguan setelah recloser dan jika sebelum recloser, maka Penyulang BTL07 akan Lock Out sehingga terjadi pemadan total pada penyulang.

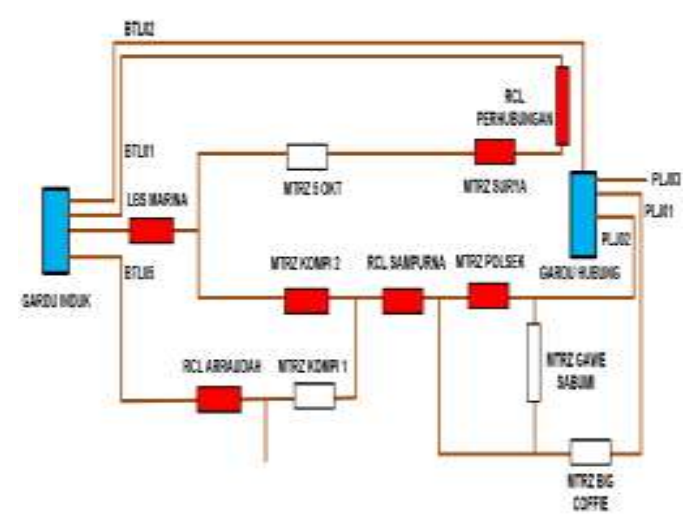

Gambar 1. Simulasi maneuver penyulang BT07 
Dalam simulasi sebelumnya titik gangguan berada pada BTL07 dengan asumsi pada keadaan tertentu akibat adanya gangnguan maka BTL07 tidak dapat melakukan suplai tegangan, mengakibatkan semua key point terjadi pemadaman. Apabila bersifat sementara maka jaringan akan normal kembali. Tetapi karena gangguan bersifat permanen maka penyulang BTL07 akan lock out. Langkah yang dapat dilakukan terhadap gangguan yang terjadi dengan melokalisir titik gangguan dan mengevakuasi daya, dengan melimpahakan beban BTL07 pada titik manuver.

\section{Analisa Saidi dan Saifi (Energy Not Saved)}

1. Saidi

$$
\begin{aligned}
& \text { a) } \quad d(\text { jan })= \\
& \left(\frac{38}{60}\right) x \frac{43920}{85898} \quad d= \\
& 0.63 \times 0.511=0.32
\end{aligned}
$$

b) $\quad d($ maret $)=\left(\frac{40}{60}\right) \times \frac{29280}{85898} \quad d=$ $0.66 \times 0.340=0.22$

c) $\quad d(m e i)=\left(\frac{0}{60}\right) x \frac{14640}{85898} \quad d=$ $0 \times 1.170=0$

d) $\quad d($ juni $)=\left(\frac{74}{60}\right) \times \frac{20404}{85898} \quad d=$ $1.23 \times 0.237=0.29$

e) $\quad d(j u l i)=\left(\frac{92}{60}\right) \times \frac{20404}{85898} \quad d=$ $1.53 \times 0.237=0.364$

2. Saifi

a) $\quad f($ jan $)=3 \times \frac{43920}{85898}=1.53$

b) $f($ maret $)=2 \times \frac{29280}{85898}=0.68$

c) $f(m e i)=1 \times \frac{14640}{85898}=0.170$

d) $\quad f($ juni $)=2 \times \frac{20404}{85898}=0.474$ e) $\quad f($ juli $)=2 \times \frac{20404}{85898}=0.477$

3. ENS (Energy Not Saved)

Ens $(K w h)=$ Beban $\times$

Lama padam

Ens $(R p)=E n s(K w H) \times 1128$

a) Ens BTL07 Jan $=9.57 \times \frac{38}{60} \times 1000=$ $2654 \mathrm{Kwh}$

Ens $\mathrm{Rp}=2654$ x $1128=2.993 .336,-$

b) Ens BTL07 Maret $=8.14 \times \frac{40}{60} \times 1000$ $=2960 \mathrm{Kwh}$

Ens $R p=2960 \times 1128=3.338 .880$

c) Ens BTL07 Mei $=0 \mathrm{Kwh} / \mathrm{Rp} 0$

d) Ens BTL07 Juni $=7.6 \times \frac{74}{60} \times 1000=$ $4687 \mathrm{Kwh}$

Ens $\mathrm{Rp}=4687$ x $1128=5.286 .560,-$

e) Ens BTL07 Juli $=4.8 \times \frac{92}{60} \times 1000=$ 2913 Kwh

Ens $R p=2913$ x $1128=3.286 .240,-$

Untuk gangguan bulan juli pada Recloser Sampurna diketahui titik gangguan berada dekat dengan Recloser sampurna pada percabangan dan hanya memadamkan 2 gardu sehingga posisi ini dapat dimanuver ke Mtrz Polsek dengan sumber tegangan pada penyulang PLJ02, manuver ini akan menyelamatkan 11 gardu mejadi 98 gardu padam dari jumlah dan sisanya dapat dimanuver melalui Mtrz Big Coffie dengan sumber tegangan melalui PLJ01 sampai berada dekat titik gangguan, manuver ini akan menyelamatkan 107 gardu.

E. Perbandingan saidi, saifi, dan ENS (Energy Not Saved) sebelum dan sesudah manuver.

Berikut ini perbandingan data sebelum dan setelah manuver dari perhitungan data gangguan penyulang dan key point bulan januari sampai juli, apabila peran Motorized dioptimalkan sebagai berikut. 
Tabel 2 tabel perbandingan data sebelum dan sesudah manuver

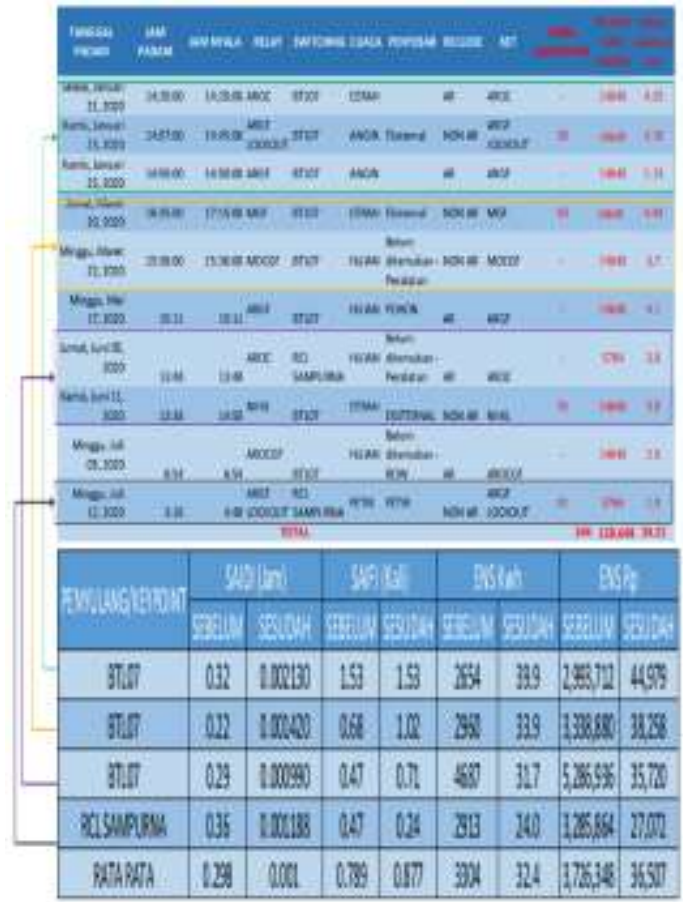

Dari data diatas, dapat dilihat terjadi penurunan durasi saidi dan ENS kWh dan ENS Rupiah pada penyulang dan recloser, namun adanya kenaikan pada kali padam saidi disebabkan karena adanya buka tutup mororized yang menyebabkan pelanggan merasakan padam sesaat selama proses manuver berlangsung.

\section{KESIMPULAN DAN SARAN}

\section{A. Kesimpulan}

1. Sistem loop sebagai uji coba yang mempertemukan beberapa penyulang melalui titik key point Motorized maupun Recloser dengan penyulang BTL07 saat dilakukan simulasi dapat menanggung pelimpahan beban yang diberikan oleh penyulang BTL07 yang mencapai hingga 8.6 MW. Beban puncak penyulang dipecah menjadi 6 titik pendistribusian energi listrik dengan panjang jaringan mengalami kenaikan dari $41.6 \mathrm{kms}$ menjadi $66.7 \mathrm{kms}$ serta drop tegangan yang terjadi maksimal adalah sebesar $1 \mathrm{KV}$ pada posisi tegangan 18.2 KV dari posisi tegangan sebelumnya 19.2 KV yang terjadi pada titik manuver BTL07 ke Mtrz 5 OKT sedangkan terjadi kenaikan tegangan tertinggi terjadi pada titik BTL07 ke Mtrz Kompi 1 dari tegangan $20 \mathrm{KV}$ menjadi $20.4 \mathrm{KV}$.

2. Optimalisasi titik manuver pada jaringan SUTM di penyulang BTL07 dapat mempercepat proses lokalisir lokasi padam dan evakuasi daya sedangkan beban serta tegangan kirim dapat ditanggung dari pelimpahan beban penyulang BTL07 sehingga saidi saifi dan potensi kehilangan ENS dapat ditekan, dengan membandingkan data gangguan bulan Januari sampai Juni dari nilai rata rata, maka saidi sebelum manuver sebesar 0.298 Jam dapat turun menjadi 0.001 jam dan nilai ENS kwh serta rupiah mengalami penurunan dari $3.304 \mathrm{kWh}$ menjadi 32,4 $\mathrm{kWh}$ atau Rp 3.726.348,- menjadi Rp 36.507,- namun pada saifi mengalami kenaikan dari 0.789 kali perpelanggan menjadi 0.877 kali perpelanggan dikarenakan proses manuver yang berlangsung.

\section{B. Saran}

Adapun saran yang dapat penulis berikan adalah sebagai berikut

1. Memperhatikan beban mampu pada penyulang yang menerima beban agar tidak melebihi daya mampu penyulang yang akan menyebabkan trip apabila melebihi daya mampu.

2. Selain dibantu dengan menaikan tegangan pada trafo GI Batulicin, adanya perencanaan rekonduktor penghantar juga baik dalam menjaga perkembangan beban sehingga tidak melampaui kemampuan 
EEICT

https://ojs.uniska-bjm.ac.id/index.php/eeict

kawat penghantar dan menurunankan energy losses.

\section{DAFTAR PUSTAKA}

Alfianto, (2015). Evaluasi Penggunaan Pemutus Tenaga (PMT) Pada Gardu Induk Sungai Juaro Palembang. Politeknik Negeri Sriwijaya. Palembang.

Afianto, (2019). Rancang Bangun Simulator Manuver Beban Ratio 4 Keypoint Berbasis Arduino Mega 2560 Dengan Tampilan Human Machine Interdace (HMI) Pada Jaringan Tegangan Menengah 20KV. Sekolah Vokasi Universitas Diponegoro. Semarang.

Gunawan, M., S. (2013). Analisa Perancangan Gardu Induk Sistem Outdoor $150 \mathrm{KV}$ di Tallasa, Kabupaten Takalar, Sulawesi Selatan. Jurnal Dimensi Teknik Elektro Vol. 1, No. 1, 37-42.

Jamaah. (2013). Analisa Beban Section Untuk Menentukan Alternatif Manuver Jaringan Distribusi 20 KV Penyulang BRG-3 PT PLN (Persero) Untul Layanan Salatiga. JTET ISSN: 2252-4908 Vol. 2 No. 3.

Hay, S., Wijaya, R., Mustamin. (2018). Analisa Daya Pada Instalasi Pemanfaatan Tenaga Listrik Menggunakan ETAP 12.6. Seminar Nasional. Teknologi Terapan Berbasis Kearifan Lokal. ISSBN: $\quad$ 978-602-71928-1-2. Universitas Halu Oleo. Sulawesi Tenggara.

Kadir. (2006). Distribusi dan Utilisasi Tenaga Listrik. Jakarta: UI Press. Hal 5 e - ISSN: $2615-2169$

p - ISSN: $2654-4296$

Penangsang, O., Hernandi, I. G. N. S., \& Wicaksono, P. H. (2012). Analisa Keandalan Sistem Distribusi Menggunakan Program Analisis Kelitrikan Transien dan Metode Section Technnique. Jurnal Teknik ITS Vol. 1. No 1. ISSN: 2301-9271.

P Indra, G. T., Arjana, I. G. D., \& Wigun, I. G. N. (2019). Analisa Rekonfigurasi Jaringan Distribusi $20 \mathrm{kV}$ Pada Penyulang Berawa Untuk Menurunkan Losses dan Drop Tegangan Penyaluran Tenaga Listrik. Jurnal Spektrum Vol 6. No 2.

PT PLN (Persero). (2010). Kriteria Disain Enjinering Konstruksi Jaringan Distribusi Tenaga Listrik. Hal 20. Jakarta Selatan.

Rokhmawati, R, I., Ramdani, F., Hawi, F., H. (2018). Evaluasi Tampilan ANtarmuka QGIS Dan ArcGIS Menggunakan Pendekatan UserCentered Desigh (UCD): Studi Kasus Fungsi Geoprocessing Tools. Jurnal Pengembangan Teknologi Informasi dan Ilmu Komputer Vol.2, No.9. Universitas Brawijaya.

Sari, P., S. (2019). Pengembangan TrainerKit Transmision Line Model TM 199 Sebagai Medi Pembelajaran Pada Mata Kuliah Transmisi Dan Distribusi Tenaga Listrik. Universitas Negeri Yogyakarta. Yogyakarta

Unit Induk Wilayah Kalselteng, Unit Pelaksana Pengatur Distribusi Banjarbaru. (2017). Laporan Pengukuran Beban dan Tegangan Penyulang. Retrieved from http://103.78.140.243/apdkalselte 
ng/opdistbeban/beban_penyulang _2017 /index.html

Unit Induk Wilayah Kalselteng, Unit Pelaksana Pengatur Distribusi Banjarbaru. (2018). Laporan Pengukuran Beban dan Tegangan Penyulang. Retrieved from http://103.78.140.243/apdkalselte ng/opdistbeban/beban_penyulang _2018/index.html

Unit Induk Wilayah Kalselteng, Unit Pelaksana Pengatur Distribusi Banjarbaru. (2019). Laporan Pengukuran Beban dan Tegangan Penyulang. Retrieved from http://103.78.140.243/apdkalselte ng/opdistbeban/beban_penyulang _2019 /index.html

Unit Induk Wilayah Kalselteng, Unit Pelaksana Pengatur Distribusi Banjarbaru. (2020). Laporan Pengukuran Beban dan Tegangan Penyulang. Retrieved from http://103.78.140.243/apdkalselte ng/opdistbeban/beban_penyulang _2020/index.html 